

\title{
Variation in treatment policies and outcome for bladder cancer in the Netherlands
}

\author{
Catharina A. Goossens Laan, Otto Visser, Michel W.J.M. Wouters, \\ Jan-Willem W. Coebergh, Cornelis J.H. van de Velde, Maarten. C.C.M. \\ Hulshof, Paul J.M. Kil
}

\section{To cite this version:}

Catharina A. Goossens Laan, Otto Visser, Michel W.J.M. Wouters, Jan-Willem W. Coebergh, Cornelis J.H. van de Velde, et al.. Variation in treatment policies and outcome for bladder cancer in the Netherlands. EJSO - European Journal of Surgical Oncology, 2010, 36, 10.1016/j.ejso.2010.06.003 . hal-00612398

\section{HAL Id: hal-00612398 https://hal.science/hal-00612398}

Submitted on 29 Jul 2011

HAL is a multi-disciplinary open access archive for the deposit and dissemination of scientific research documents, whether they are published or not. The documents may come from teaching and research institutions in France or abroad, or from public or private research centers.
L'archive ouverte pluridisciplinaire HAL, est destinée au dépôt et à la diffusion de documents scientifiques de niveau recherche, publiés ou non, émanant des établissements d'enseignement et de recherche français ou étrangers, des laboratoires publics ou privés. 


\section{Accepted Manuscript}

Title: Variation in treatment policies and outcome for bladder cancer in the Netherlands

Authors: Catharina A. Goossens Laan, MDOtto Visser, MD, PhDMichel W.J.M. Wouters, MDJan-Willem W. Coebergh, MD PhDCornelis J.H. van de Velde, MD


PhDMaarten. C.C.M. Hulshof, MD, PhDPaul J.M. Kil, MD PhD

PII: S0748-7983(10)00158-7

DOI: 10.1016/j.ejso.2010.06.003

Reference: $\quad$ YEJSO 2991

To appear in: European Journal of Surgical Oncology

Received Date: 19 April 2010

Accepted Date: 1 June 2010

Please cite this article as: Goossens Laan CA, Visser O, Wouters MWJM, Coebergh JWW, van de Velde CJH, Hulshof CCM, Kil PJ,. Variation in treatment policies and outcome for bladder cancer in the Netherlands, European Journal of Surgical Oncology (2010), doi: 10.1016/j.ejso.2010.06.003

This is a PDF file of an unedited manuscript that has been accepted for publication. As a service to our customers we are providing this early version of the manuscript. The manuscript will undergo copyediting, typesetting, and review of the resulting proof before it is published in its final form. Please note that during the production process errors may be discovered which could affect the content, and all legal disclaimers that apply to the journal pertain. 
1 Variation in treatment policies and outcome for bladder cancer in the Netherlands

3 Catharina A. Goossens - Laan MD1, Otto Visser MD, PhD², Michel W.J.M. Wouters

$4 \mathrm{MD}^{3}$, Jan-Willem W. Coebergh, MD PhD ${ }^{4}$, Cornelis J.H. van de Velde, MD PhD

5 Maarten. C.C.M. Hulshof, MD, PhD' ${ }^{6}$ Paul J.M. Kil, MD PhD7

6 On behalf of the 'Quality of cancer care' task force of the Signalling Committee

7 Cancer of the Dutch Cancer Society (the committees full report is available on 8 www.kwfkankerbestrijding.nl)".

9 1St. Elisabeth Hospital, department of Urology, Tilburg, The Netherlands, affiliated with

10 Utrecht University Medical Center, department of Urology; ${ }^{2}$ Comprehensive Cancer

11 Centre Amsterdam, Amsterdam, The Netherlands; 3Department of Surgical

12 Oncology, The Netherlands Cancer Institute, Antoni van Leeuwenhoek Hospital, 13 Amsterdam, The Netherlands; ${ }^{4}$ Comprehensive Cancer Centre South, Eindhoven, 14 The Netherlands 5Leiden University Medical Center, Surgery, Leiden, The 15 Netherlands; ${ }^{6}$ Department of Radiotherapy, Academic Medical Center Amsterdam, 16 Amsterdam;7 St. Elisabeth Hospital, department of Urology, Tilburg, The Netherlands.

17 Corresponding author: C.A. Goossens - Laan,

18 Department of Urology, University Medical Centre Utrecht; HP:C04.236 


\section{Abstract}

Aim: To describe the population-based variation in treatment policies and outcome for bladder cancer in the Netherlands.

Methods: All newly diagnosed patients with primary bladder cancers during 2001 2006 were selected from the Netherlands Cancer Registry $(n=29,206)$. Type of primary treatment was analysed according to Comprehensive Cancer Centre region, hospital type (academic, non-academic teaching or other hospitals) and volume $(\leq 5$, 6-10 or $>10$ cystectomies yearly). For stage II-III patients undergoing cystectomy we analyzed the proportion of lymph node dissections and 30-days mortality.

Results: $44 \%$ of patients with stage II-III bladder cancer underwent cystectomy, while $26 \%$ were not treated with curative intent. Cystectomy was the preferred option in three of nine regions, radiotherapy in two, and two regions waived curative treatment more often. Between 2001 and 2006 the number of cystectomies increased with $20 \%$ $(n=108)$. Twenty-one percent $(n=663)$ of these procedures were performed in 44 low volume hospitals. In $79 \%$ of the cystectomies lymph node dissections were performed, more often in high and medium-volume centers $(82 \%$ and $81 \%$ respectively) than in low-volume hospitals $(71 \%$, the odds ratio being 1.5$)$. The overall 30 -days postoperative mortality rate was $3.4 \%$ and increased with older age. 
41 policies for muscle-invasive bladder cancer in the Netherlands showed regional 42 preferences and a gradual increase of cystectomy. Cystectomy albeit considered as 43 golden standard, was performed in a minority of the muscle-invasive cases. In high44 volume institutions, lymph node dissection rates were higher and post-operative 45 mortality rates were lower.

46 Keywords: Bladder cancer, mortality rate, treatment, volume surgery, population47 based. 
54 females. $(2 ; 3)$

\section{Introduction}

In the Netherlands, bladder cancer is the fifth common tumor in men, and the seventh in women.(1) While the incidence of non-invasive bladder cancer in the Netherlands has been increasing, it is decreasing for invasive bladder cancer. In recent years, the mortality rates from bladder cancer decreased among males, contrasting A patient with newly diagnosed non muscle-invasive disease may be cured with local treatment only; i.e. one or multiple transurethral resections of the tumor(s)(TUR-BT) with or without subsequent bladder instillations. Cystectomy is the preferred therapy, for patients with muscle-invasive bladder cancer (MIBC) and for patients who underwent unsuccessful local treatment of non muscle-invasive bladder cancer. When a patient is not eligible for a cystectomy due to co-morbidity, or old age or patient preference, radiotherapy is the second best option.(4)

Increasing evidence for a positive association between quality of care in cancer treatment in relation to volume and infrastructure (5-7) led us to explore variations in staging and treatment policies and its outcome for bladder cancer in the Netherlands. 


\section{Patients and Methods}

Cancer registry data.

All patients with primary bladder tumours newly diagnosed in the Netherlands between January 1, 2001 and December 31, 2006 were selected from the population-based Netherlands Cancer Registry, with complete national coverage. Dutch hospitals are served in the nine regions by the largely coordinating and facilitating Comprehensive Cancer Centers (CCC). In the hospitals, registration clerks of the CCCs extract information for the registry from the medical records, notified by the Dutch National Pathology database (PALGA). A variety of data are collected, i.e. on demographics, morphology, stage at diagnosis and primary treatment (planned in the six months following diagnosis) and vital status, date of follow-up or death. Tumor site and morphology were coded according to the International Classification of Diseases for Oncology (ICD-O).(5) Quality of data is generally considered to be high and completeness was estimated to be more than $95 \% .(6 ; 7)$

\section{Hospitals and regions.}

Patients of all ( $N=97)$ hospitals in the Netherlands were included in this study. Hospitals were grouped into three categories, i.e. 1) 9 academic hospitals 2) non-academic hospitals with teaching facilities for urology residents 3) other hospitals (community hospitals). The influence of a radiotherapy department on the 
choice of treatment was also investigated. Type of primary treatment was analysed according to geographic region (subdivided according to age and stage), hospital type and annual volume $(\leq 5,>5-10$ or $>10$ cystectomies yearly). Variations in treatment policies, according to age and stage were assessed in the nine regions.

\section{Data analysis.}

Data analysis was done with anonymised data. Stage grouping in this study was done according to the UICC TNM classification, 6th edition.(8) CTNM was used for the diagnosis and general treatment policies including all patients and pTNM for subset analysis of cystectomy cases. Excluded from analysis were bladder tumors without histology proven diagnosis, sarcomas, lymphomas, bladder cancer only found postmortem, incomplete registrations, and tumour recurrence (except when stage 0 progressed into stage 1 or higher). Local treatment is defined as one or multiple transurethral resections of the tumor often followed by bladder installations. Only the initial treatment (within six months after diagnosis) for every new tumour was registered, thereby disregarding cystectomy for an initial non muscle-invasive tumour that progressed to muscle-invasive disease more than six months after the first diagnosis or a salvage cystectomy after radiotherapy. When the initial treatment took more than six months to complete, for example in case neo-adjuvant chemotherapy preceded the cystectomy, the whole treatment was registered. 
Primary treatment was grouped according to local resection or no treatment (local

\section{7} treatment), cystectomy, radiotherapy or chemotherapy. A patient who underwent cystectomy and radiotherapy or chemotherapy was classified as cystectomy. A 109 patient receiving radiotherapy as well as chemotherapy was classified as 110 radiotherapy. Curative and palliative cystectomy or radiotherapy could not be 111 distinguished.

112 A subset of patients was analyzed for the proportion of lymph node dissections

113 according to surgical volume and the 30 and 60 day-mortality rate after cystectomy.

114 For this category the years of analysis were restricted from 2004 until 2006 as the 115 date of cystectomy was not available for all cases in earlier years.

Statistical methods.

118 Logistic regression analysis was performed to examine the influence of age at 119 diagnosis (<60,60-74, $\geq 75$ years), gender, stage, type of hospital, hospital volume, 120 CCC-region on the odds of receiving surgery (cystectomy), radiotherapy, and on 121 either surgery or radiotherapy. All analyses, including the logistic regression 122 analyses, were performed in STATA, version 10. Results were considered 123 statistically significant for $p<0.05$. 


\section{Results}

125

126 Table 1.

During 2001-2006, 29,206 patients (78\% male) were diagnosed with primary bladder cancer. Six percent of all new patients were diagnosed in academic hospitals, $23 \%$ in non-academic hospitals with a teaching facility for urology and $71 \%$ in the other hospitals. Patient, hospital, regional and treatment characteristics are presented in

\section{Treatment of superficial or non muscle-invasive bladder cancer}

At first diagnosis, $71 \%$ of the patients had non muscle-invasive primary bladder cancer, $73 \%$ in males and $64 \%$ in females. Seventy percent of the non muscleinvasive cancers were non-invasive papillary carcinomas (Ta or stage $0 a$ ), while $30 \%$ were cancers invading the subepithelial connective tissue only (T1 or stage I). Flat tumours (carcinoma in situ or stage Tis) represented five percent of the non-muscle invasive cancers. Initial treatment of bladder cancer in the Netherlands according to stage is shown in figure 1 . The vast majority of patients with non muscle-invasive cancers received TUR-BT (with or without instillations) (Tis 94\%, Ta grade 1-2 99\%, Ta grade 3 97\%, Ta grade unknown 96\%; T1 grade 1-2 96\%, T1 grade $390 \%$, T1 grade unknown $91 \%$ ). Cystectomy was performed in $1.5 \%$ of the patients in stage Tis, $<0.5 \%$ in stage Ta and $2 \%$ in low and medium grade T1-tumours. The treatment remained unknown in $4 \%$ of patients (Tis $4 \%$, Ta grade $1-21 \%$, Ta grade $31 \%$, Ta 
145 grade unknown 4\%; T1 grade 1-2 1\%, T1 grade $31 \%$, T1 grade unknown 3\%). High

146 grade T1-tumors were diagnosed in 3,043 patients (53\% of all T1 tumors). Seven 147 percent of T1G3 tumors underwent a cystectomy, and $2 \%$ received radiotherapy. A

148 multivariate regression analysis revealed cystectomy to be performed significantly 149 less in older patients ( $\geq 75$ years; OR 0.2, $p=0.000$ ) and more frequent in region 7 150 (OR 1.82, $\mathrm{p}<0.0035)$ in stage T1G3.

\section{Treatment of muscle-invasive bladder cancer}

153 Almost 8,000 patients with MIBC were diagnosed in 2001-2006 (on average 1,300

154 annually). A cystectomy was performed in $36 \%$ of all muscle-invasive cases. In stage 155 II $43 \%$ underwent a cystectomy, $31 \%$ received radiotherapy, $<1 \%$ chemotherapy and $15626 \%$ of the patients received only local treatment or no treatment. $44 \%$ of stage III 157 patients underwent a cystectomy, 31\% received radiotherapy, 1\% chemotherapy, 158 and $25 \%$ received only local treatment or no treatment. $17 \%$ of newly diagnosed 159 patients with stage IV underwent cystectomy, while 19\% received radiotherapy and $16016 \%$ with chemotherapy. $48 \%$ of the stage IV patients received no therapy or only

161 local treatment.

162 An increasing proportion of stage II patients underwent cystectomy, from $39 \%$ in 1632001 to $47 \%$ in 2006 , but remaining more or less constant in stage III (39\% 164 cystectomies in 2001 and $38 \%$ in 2006). Utilization of radiotherapy decreased from $16534 \%$ to $27 \%$ in stage II and from $36 \%$ to $30 \%$ in stage III. 
166 Figure 2 shows that the proportion of patients undergoing cystectomy for muscle-

167 invasive cancer strongly decreased with age. In a multivariate analysis the OR of 168 patients of $60-74$ years versus $<60$ years was $0.49(p=0.000)$ and the $O R$ of $\geq 75$

169 years versus $<60$ was $0.06(p=0.000)$. Radiotherapy was more often administered in

170 older patients (60-74 yr OR 2.0, $p=0.000 ; \geq 75 \mathrm{yr}$ OR 5.2, $p=0.000)$. The chance of

171 having one of both treatments declines with increasing age (60-74 yr OR 0.65, p <

$172 \quad 0.002 ; \geq 75$ yr OR 0.18, $p=0.000)$.

173 Patients were more likely to undergo a curative treatment in stage III than for stage II

174 (OR 1.6, $p=0.000)$. More cystectomies were performed in comparison to

175 radiotherapy (stage III: OR cystectomy $1.5, p=0.000$ vs. radiotherapy $0.99, p<0.9$ )

176 (Figure 3). Women more often underwent cystectomy (OR cystectomy 1.2, p $<0.016$;

177 OR radiotherapy $0.75(p=0.000))$, contrasting radiotherapy for men.

178 The likelihood for receiving a specific kind of treatment is not dependent on the type 179 of hospital where the initial diagnosis was made. The availability of a radiation

180 department in the hospital of diagnosis did not affect the likelihood for receiving 181 radiotherapy. However, there are strong regional preferences for specific treatments

182 as shown for patients with stage II disease (figure 3). Among patients below 75 years

183 of age 60 to $77 \%$ underwent cystectomy in the various regions, and 10 to $28 \%$

184 underwent radiotherapy. The chance of undergoing a cystectomy in stage II-III 185 disease was higher in region 2, 3 and 6 in comparison to region 1 (OR 1.4, p < 0.005;

186 OR $1.9, p=0.000$ and OR $1.3, p<0.024)$. The chance of undergoing radiotherapy in 
187

188

stage II-III disease was lower in region 2, 3, 6, and 8 in comparison to region 1 (OR 0.8, $p<0.016$; OR 0.6, p = 0.000, OR 0.8, p $<0.031$ and OR 0.7, p $<0.035$ respectively). The differences in radiotherapy mainly followed differences in the application of interstitial radiotherapy (brachytherapy): the regions with a high percentage of radiotherapy were the same as those performing brachytherapy more often (region 1 and 7). In two regions (region 4 and 9) a curative treatment was performed clearly less often (OR 0.7, $p<0.009$; OR $0.6, p=0.000$ ) than in other regions.

\section{Cystectomy}

Between 2001 and 2006 the total annual number of cystectomies increased 23\% (from 472 to 585). Eleven percent of the cystectomies were performed in clinically non-muscle invasive disease, $77 \%$ were in clinical stage II or III (T2-T4a). Twelve percent were clinical stage IV. The proportion of clinically potentially understaged patients ranged from $44 \%$ in clinical stage I, $48 \%$ in stage II and $22 \%$ in stage III (table 2). The proportion of clinically overstaged patients ranged from $12 \%$ in clinical stage III and $21 \%$ in clinical stage IV (Table 2 ).

Sixty percent of the operations were performed in community hospitals. The contribution of specialized centers was slightly increasing from $13 \%$ in 2001 to $18 \%$ in 2006. In 44 hospitals five or less cystectomies were done annually, accounting for $21 \%$ of all patients, 36 hospitals an average of $6-10$ operations, together comprising 
208

209

212 often in specialized centers in comparison to the community hospitals (OR 2.7;

$213 \mathrm{p} \leq 0,000)$, and significantly more often in median and high-volume hospitals ( $81 \%$ and

$21482 \%$ ) in comparison to low-volume hospitals (71\%) (OR 1.47 (6-10/year) and OR

2151.52 ( $\geq 10 /$ year) vs. low-volume hospitals; $p=0,027$, and $p=0,043$ ).

216 The overall 30-days mortality rate after cystectomy in $2004-2006$ was $3.4 \%$. (Table 3 )

217 This rate rose with increasing age of the patient from $1.1 \%$ below the age of $60,3.1 \%$ 218 for $60-74$ years and $7.4 \%$ for patients 75 years or older. In the high-volume centers 219 the mortality rate was significantly lower (1.2\%; OR 0.2 vs. low-volume hospitals; $220 \mathrm{p}=0.002$ ). Mortality rates after 60 and 90 days were higher (all hospitals combined $2215.7 \%$ and $7.7 \%$ and high volume $3.1 \%$ and $4.9 \%$ ), but the relative difference in 222 mortality rate between the high, medium and low volume hospitals remained 223 unchanged.

\section{Discussion.}

226 This paper summarizes the major variations in treatment policies in the period 20012272006 for different regions and hospital types in the Netherlands. Remarkable regional 228 differences in the choice of primary treatments were found. Availability of interstitial 
229 radiotherapy (brachytherapy) explained much of the variation in frequency of

230 radiotherapy use in both stage II and III disease, with subsequent lower cystectomy

231 rates in these regions (Figure 3 ). Nevertheless, in two regions curative treatment

232 options (radiotherapy or cystectomy) were clearly used less often than in other 233 regions, suggesting disparities in the chance of receiving optimal treatment for 234 patients with bladder cancer.

235 No difference in choice of treatment was found in the three different types of hospitals

236 (academic hospital, training hospital or community hospital). Lymph node dissection

237 and mortality rates in cystectomy procedures differed with hospital volumes. Patients

238 in high volume centers exhibited lower mortality rates than in low volume centers.

240 American and European guidelines indicate that a patient with a pT1G3 tumor should

241 initially receive BCG intravesical therapy, although cystectomy can be considered.

$242(4 ; 9 ; 10)$. The majority $(90 \%)$ of patients with the high grade T1-tumours in our study 243 received initially local therapy only (TURBT with BCG-instillations). We may conclude 244 that this is in accordance with the current guidelines.

245 Radical cystectomy is considered the 'golden standard' for stage II and III (muscle246 invasive) bladder cancer, being reinforced by recent updates of European and Dutch

247 guidelines. $(4 ; 11)$ In view of these guidelines the low number of cystectomies for 248 MIBC cancer patients (36\%) was remarkable. Even in MIBC patients below 75 years 
249 the number of cystectomies was low (stage II 65\%; stage III 68\%), but seems to

250 increase over time.

251 However, our data are similar to a recent Swedish population-based study. The

252 curative intent for patients with clinical stage T2_T4 bladder cancer was $41 \%$ (by

253 means of radiotherapy (8\%) or cystectomy $(33 \%)$. For patients younger than 75

254 years, the curative intent of total treatment arm was $62 \%$.(12) In comparison to the

255 Sweden, the Dutch percentage of cystectomy was slightly higher, moreover

256 increasing with $8 \%$ over this study period.

257 Our study shows that high procedure volume for cystectomy was statistically 258 significantly associated with lower postoperative mortality, especially related to that in

259 hospitals with a procedural annual volume of $\leq 5$ cystectomies, where a 30-day 260 mortality of $6.4 \%$ was found. In the Netherlands there are 44 of these low volume

261 hospitals and together they perform 111 cystectomies a year ( $21 \%$ of all patients). A

262 third of patients (36\%) underwent cystectomy in high volume hospitals, which have a

263 significantly lower mortality (1.2\%), while most patients $(46 \%)$ are operated in

264 medium volume hospitals with annually 6-10 cystectomies and a mortality rate of $2653.6 \%$.

266 Mounting evidence suggests that high procedure volume of complex operations is 267 related with lower operative mortality after high-risk cancer surgeries (cystectomy, 268 esophagectomy, pancreatectomy, etc).(13;14), but the difference might partly be 269 affected by selective referral of relatively healthy patients of higher SES. Only one 
270 Dutch study compared post-operative mortality of patients undergoing cystectomy for

271 low-volume hospitals with an oncologic center.(15) The postoperative mortality was

272 unsignificantly lower in the oncologic center $(1.8 \%$ versus $3.5 \%)$. The present

273 national population-based study is more suggestive because of its power.

275 Nevertheless, our study has several limitations. Though data on age and gender 276 were available, our study lacks information on co-morbidities and performance status 277 of patients. Though several studies have shown that radical cystectomy is a safe 278 option in elderly fit patients, a poor performance status of patients might jeopardize 279 surgical treatment and lead to a choice for radiotherapy or palliative treatment only.(16-19). A study in two CCC-regions showed co-morbid conditions in elderly 281 patients to affect the choice of treatment (submitted). There could also be the patient 282 preference to choose for a bladder sparing approach, although there is no such 283 differential information available within the Netherlands. Then, only the cystectomies 284 six months after first diagnoses were taken into account, so the real cystectomy 285 volume per hospital may be larger. Up to $30 \%$ of patients with superficial tumors 286 involves in $\geq$ T1-tumors,(11) of which an unknown percentage will undergo 287 cystectomy. Though a re-biopsy is planned within 6 weeks after local resection for T1 288 tumors, and will be take place within the six months interval after first diagnosis. 
In most industrialized countries, medical disciplines, insurance companies and policy makers discuss potential improvements of patient safety and quality of health care.(23) In the literature more and more studies advocate specific volume standards for high risk cancer operations, such as $\geq 11$ cystectomies a year. $(14 ; 20 ; 21)$ In the United States the Leapfrog group, a large coalition of insurance companies encourages patients to have their operation in a high volume referral center since 2000 , but there have been no reports about actual overall improvement in outcome from these volume-based referral initiatives. Apparently, focusing on volume only, which is only a proxy for quality of care, is not enough for improving care-processes and outcome.

Moreover, complex surgical procedures like radical cystectomy have more dimensions than mortality and depend on more than hospital volume alone. Other factors include surgeon's competence, the hospitals infrastructure e.g. quality of critical care units and broad consultant expertise, the implementation of standard pathways and protocols.(22) Most important, the surgical team should be capable to handle all postoperative complications. In addition to post-operative mortality rates, patient outcome can also be measured using complication and recurrence rates, number of resected lymph nodes, surgical margins, survival rate and last but not least by the impact on quality of life.(23) To provide optimal quality of care for patients with muscle-invasive bladder cancer, quality of care indicators could be used for measuring and monitoring one's own performance.(24) The facilitating cancer 
registries of the Comprehensive Cancer Centers could greatly assist by

311 independently collecting extra clinical data at regional or national scale and provide

312 feedback to attending physicians and possible specific audits undertaken by them.

314 This paper summarizes the population-based variation in treatment policies for

315 bladder cancer in the Netherlands in the period 2001-2006. Exploring population

316 based cancer registries for differences in patterns of care can give insight in

317 opportunities for improvement and could lead to a change in treatment strategies.

319 Conflict of interest statement:

320 C.J.H. van de Velde, president of the ESSO and M.W.J.M. Wouters are both guest321 editors of this special issue of the EJSO. O. Visser and J.W. Coebergh both work at a 322 Comprehensive Cancer Center.

324 Acknowledgements: The authors thank the registration teams of the Comprehensive

325 Cancer Centres for the collection of data for the Netherlands Cancer Registry and the 326 investigators of the Netherlands Cancer Registry involved in the analyses of quality of 327 cancer care. 
Reference List

1. The Netherlands Cancer Registry. Incidence of invasive tumors, specified for sex and localisation for year of incidence (1989-2007). [Online http://www.ikcnet.nl/page.php?nav id=41\&id=2863]. 1-1-2009.

2. Ferlay J, Randi G, Bosetti C, Levi F, Negri E, Boyle P, La VC. Declining Mortality From Bladder Cancer in Europe. BJU Int 2008; 101(1): 11-9.

3. Karim-Kos HE, de VE, Soerjomataram I, Lemmens V, Siesling S, Coebergh JW. Recent Trends of Cancer in Europe: a Combined Approach of Incidence, Survival and Mortality for 17 Cancer Sites Since the 1990s. Eur J Cancer 2008; 44(10): 1345-89.

4. Batterman JJ, Feller N, Hamelers-Paulus HWG, de Reijke TM, Witjes JA. Guideline Diagnostics, treatment and follow-up of the Urothelial Cell Carcinoma of the bladder. 2008, Dutch Projectgroep Guideline Bladder Cancer; the Netherlands Cancer Registry.

5. Hollenbeck BK, Wei Y, Birkmeyer JD. Volume, Process of Care, and Operative Mortality for Cystectomy for Bladder Cancer. Urology 2007; 69(5): 871-5.

6. Wouters M, Krijen P, Le Cessie S, gooiker G, Guicherit O, Marinelli A, Kievit J, Tollenaar R. Volume- or Outcome-Based Referral to Improve Quality of Care for Esophageal Cancer Surgery in the Netherlands. Journal of Surgical Oncology 2009; 99(8):481-7.

7. van Heek NT, Kuhlmann KF, Scholten RJ, de Castro SM, Busch OR, van Gulik TM, Obertop H, Gouma DJ. Hospital Volume and Mortality After Pancreatic Resection: a Systematic Review and an Evaluation of Intervention in the Netherlands. Ann Surg 2005; 242(6): 781-8, discussion.

8. Fritz A. International Classification of Diseases for Oncology. Geneva: World Health Organization, 2000.

9. Schouten LJ, Jager JJ, van den Brandt PA. Quality of Cancer Registry Data: a Comparison of Data Provided by Clinicians With Those of Registration Personnel. Br J Cancer 1993; 68(5): 974-7.

10. Schouten LJ, Hoppener P, van den Brandt PA, Knottnerus JA, Jager JJ. Completeness of Cancer Registration in Limburg, The Netherlands. Int J Epidemiol 1993; 22(3): 369-76.

11. Sobin LH, Wittekind C. TNM Classification of Malignant Tumours, 6th ed. 2002. New York, Wiley-Liss.

12. Witjes JA. Management of the First Recurrence of T1G3 Bladder Cancer: Does Intravesical Chemotherapy Deserve a Chance? Urol Oncol 2009; 27(3): 322-4.

13. Hall MC, Chang S, Dalbagni G, Pruthi RS, Schellhammer PF, Seigne jD, Skinner EC, Wolf JS, Bell HS, Florer PM, Glickham D, Pope S, Hubbard H, Budd E, Folmer M, Moore K, Kebe K. Management of Nonmuscle Invasive Bladder Cancer: (Stages Ta,T1, and Tis): Revised (2007). 10-1-2007. American Urological Association Education and Research, Inc. 
14. Jakse G, Algaba F, Fossa S, Stenzyl A, Sternberg C. Guidelines on bladder cancer,muscleinvasive and metastatic. 2006. European association of Urology.

15. Jahnson S, Damm O, Hellsten S, Holmang S, Liedberg F, Ljungberg B, Malmstrom PU, Mansson W, Stromberg F, Wijkstom H. A Population-Based Study of Patterns of Care for Muscle-Invasive Bladder Cancer in Sweden. Scand J Urol Nephrol 2009; 43(4): 271-6.

16. Hollenbeck BK, Dunn RL, Miller DC, Daignault S, Taub DA, Wei JT. Volume-Based Referral for Cancer Surgery: Informing the Debate. J Clin Oncol 2007; 25(1): 91-6.

17. McCabe JE, Jibawi A, Javle P. Defining the Minimum Hospital Case-Load to Achieve Optimum Outcomes in Radical Cystectomy. BJU Int 2005; 96(6): 806-10.

18. de Vries RR, Visser O, Nieuwenhuijzen JA, Horenblas S. Outcome of Treatment of Bladder Cancer: a Comparison Between Low-Volume Hospitals and an Oncology Centre. World J Urol 2010.

19. Chang SS, Alberts G, Cookson MS, Smith JA, Jr. Radical Cystectomy Is Safe in Elderly Patients at High Risk. J Urol 2001; 166(3): 938-41.

20. Clark PE, Stein JP, Groshen SG, Cai J, Miranda G, Lieskovsky G, Skinner DG. Radical Cystectomy in the Elderly: Comparison of Clincal Outcomes Between Younger and Older Patients. Cancer 2005; 104(1): 36-43.

21. Lund L, Jacobsen J, Clark P, Borre M, Norgaard M. Impact of Comorbidity on Survival of Invasive Bladder Cancer Patients, 1996-2007: A Danish Population-Based Cohort Study. Urology 2010; 75(2):393-8.

22. Froehner M, Brausi MA, Herr HW, Muto G, Studer UE. Complications Following Radical Cystectomy for Bladder Cancer in the Elderly. Eur Urol 2009; 56(3): 443-54.

23. Albertsen P. Regionalizing urologic cancer care: appropriate health care policy?Urol Oncol 2010; 28(1):1-3.

24. Elting LS, Pettaway C, Bekele BN, Grossman HB, Cooksley C, Avritscher EB, Saldin K, Dinney $\mathrm{CP}$. Correlation Between Annual Volume of Cystectomy, Professional Staffing, and Outcomes: a Statewide, Population-Based Study. Cancer 2005; 104(5): 975-84.

25. Dudley RA, Johansen KL, Brand R, Rennie DJ, Milstein A. Selective Referral to High-Volume Hospitals: Estimating Potentially Avoidable Deaths. JAMA 2000; 283(9): 1159-66.

26. Black PC, Brown GA, Dinney CP. Should Cystectomy Only Be Performed at High-Volume Hospitals by High-Volume Surgeons? Curr Opin Urol 2006; 16(5): 344-9.

27. Herr HW, Faulkner JR, Grossman HB, Natale RB, deVere WR, Sarosdy MF, Crawford ED. Surgical Factors Influence Bladder Cancer Outcomes: a Cooperative Group Report. J Clin Oncol 2004; 22(14): 2781-9.

28. Goossens-Laan C, Kil P, Oudshoorn F, Roukema A, Bosch R, De Vries J. Quality of Care Indicators for Muscle-Invasive Bladder Cancer. Urology 74[4], S104-S105. 
404 Table 1 Characteristics of bladder cancer in the Netherlands, 2001-2006

all cases

Year of diagnosis

2001
2002
2003
2004
2005
2006
Sex
Males
Females

Age category

$<60$

60-74

75 or older

Clinical TNM-stage

Tis

Ta

I

II

III

IV

Unknown

Morphological classification

squamous cell carcinoma

transitional cell carcinoma

adenocarcinoma

undifferentiated carcinoma

neuro-endocrine carcinoma

Hospital of first diagnosis university hospital/oncological centre non-academic teaching hospitals other hospitals (community)

Number of cases

29,206

$\begin{array}{ll}4,473 & 15.3 \% \\ 4,591 & 15.7 \% \\ 4,740 & 16.2 \% \\ 4,992 & 17.1 \% \\ 5,154 & 17.6 \% \\ 5,256 & 18.0 \%\end{array}$

$22,727 \quad 77.8 \%$

$6,479 \quad 22.2 \%$

$5,745 \quad 19.7 \%$

$12,780 \quad 43.8 \%$

$10,681 \quad 36.6 \%$

$973 \quad 3.3 \%$

$13,582 \quad 46.5 \%$

$6,267 \quad 21.5 \%$

$4,505 \quad 15.4 \%$

$1,126 \quad 3.9 \%$

$2,349 \quad 8.0 \%$

$404 \quad 1.4 \%$

$343 \quad 1.2 \%$

$28,369 \quad 97.1 \%$

$195 \quad 0.7 \%$

$107 \quad 0.4 \%$

$192 \quad 0.7 \%$

$1,779 \quad 6.1 \%$

$6,679 \quad 22.9 \%$

$20,745 \quad 71.0 \%$

Radiotherapy facilities in the hospital

\begin{tabular}{l} 
No \\
Yes \\
Comprehensive cancer centre \\
\hline 1 \\
2 \\
3 \\
4 \\
5 \\
6 \\
7 \\
8 \\
9
\end{tabular}

$23,629 \quad 80.9 \%$

$5,577 \quad 19.1 \%$

$4,020 \quad 13.8 \%$

$2,351 \quad 8.0 \%$

$2,188 \quad 7.5 \%$

$5,292 \quad 18.1 \%$

$2,764 \quad 9.5 \%$

$4,436 \quad 15.2 \%$

$4,169 \quad 14.3 \%$

$1,827 \quad 6.3 \%$

$2,156 \quad 7.4 \%$ 
406 Table 2

407 Pathological stage after cystectomy according to clinical stage of patients with

408 bladder cancer in the Netherlands 2001-2006.

\begin{tabular}{|c|c|c|c|c|c|c|c|c|c|c|c|c|c|c|c|}
\hline \multirow[b]{2}{*}{ Clinical stage } & \multicolumn{15}{|c|}{ Pathological stage } \\
\hline & \multicolumn{2}{|c|}{ Tis } & \multicolumn{2}{|c|}{$\mathrm{Ta}$} & \multicolumn{2}{|l|}{$\mathrm{I}$} & \multicolumn{2}{|l|}{ II } & \multicolumn{2}{|l|}{ III } & IV & \multicolumn{3}{|c|}{ unknown } & \multirow[t]{2}{*}{ Total } \\
\hline & $\mathrm{n}$ & $\%$ & $\mathrm{n}$ & $\%$ & $\mathrm{~N}$ & $\%$ & $\mathrm{n}$ & $\%$ & $\mathrm{n}$ & $\%$ & $n$ & $\%$ & $\mathrm{n}$ & $\%$ & \\
\hline Tis & 13 & $87 \%$ & - & - & 2 & $13 \%$ & - & - & - & - & - & - & - & - & 15 \\
\hline $\mathrm{Ta}$ & 1 & $2 \%$ & 35 & $85 \%$ & 1 & $2 \%$ & 2 & $5 \%$ & 0 & $0 \%$ & 1 & $2 \%$ & 1 & $2 \%$ & 41 \\
\hline I & & & & & 173 & $56 \%$ & 61 & $20 \%$ & 49 & $16 \%$ & 27 & $9 \%$ & - & - & 310 \\
\hline II & & & & & 48 & $2 \%$ & 958 & $49 \%$ & 643 & $33 \%$ & 299 & $15 \%$ & - & - & 1,948 \\
\hline III & & & & & 5 & $1 \%$ & 57 & $11 \%$ & 340 & $66 \%$ & 112 & $22 \%$ & - & - & 514 \\
\hline IV & & & & & 2 & $1 \%$ & 23 & $6 \%$ & 52 & $14 \%$ & 291 & $79 \%$ & - & - & 368 \\
\hline unknown & & & & & - & - & - & - & - & - & - & - & 3 & $100 \%$ & 3 \\
\hline
\end{tabular}


409 Table 3

410 Relation of average annual volume of cystectomy with lymph node dissection and 30

411 day-mortality rate in newly diagnosed patients with bladder cancer in the

412 Netherlands, 2004-2006.

\begin{tabular}{|l|c|c|}
\hline Average volume & Proportion of lymph node & 30 day (60 day) mortality rate \\
& dissections & $6.4 \%(8.6 \%)$ \\
\hline$<=5$ per year & $71 \%$ & $3.6 \%(6.4 \%)$ \\
$>$-10 per year & $81 \%$ & $1.2 \%(3.1 \%)$ \\
$>10$ per year & $82 \%$ & $3.4 \%(5.7 \%)$ \\
Total & $79 \%$ & \\
\hline
\end{tabular}


414 Figure 1

415 Treatment of newly diagnosed patients with bladder cancer according to clinical

416 stage, the Netherlands 2001-2006.

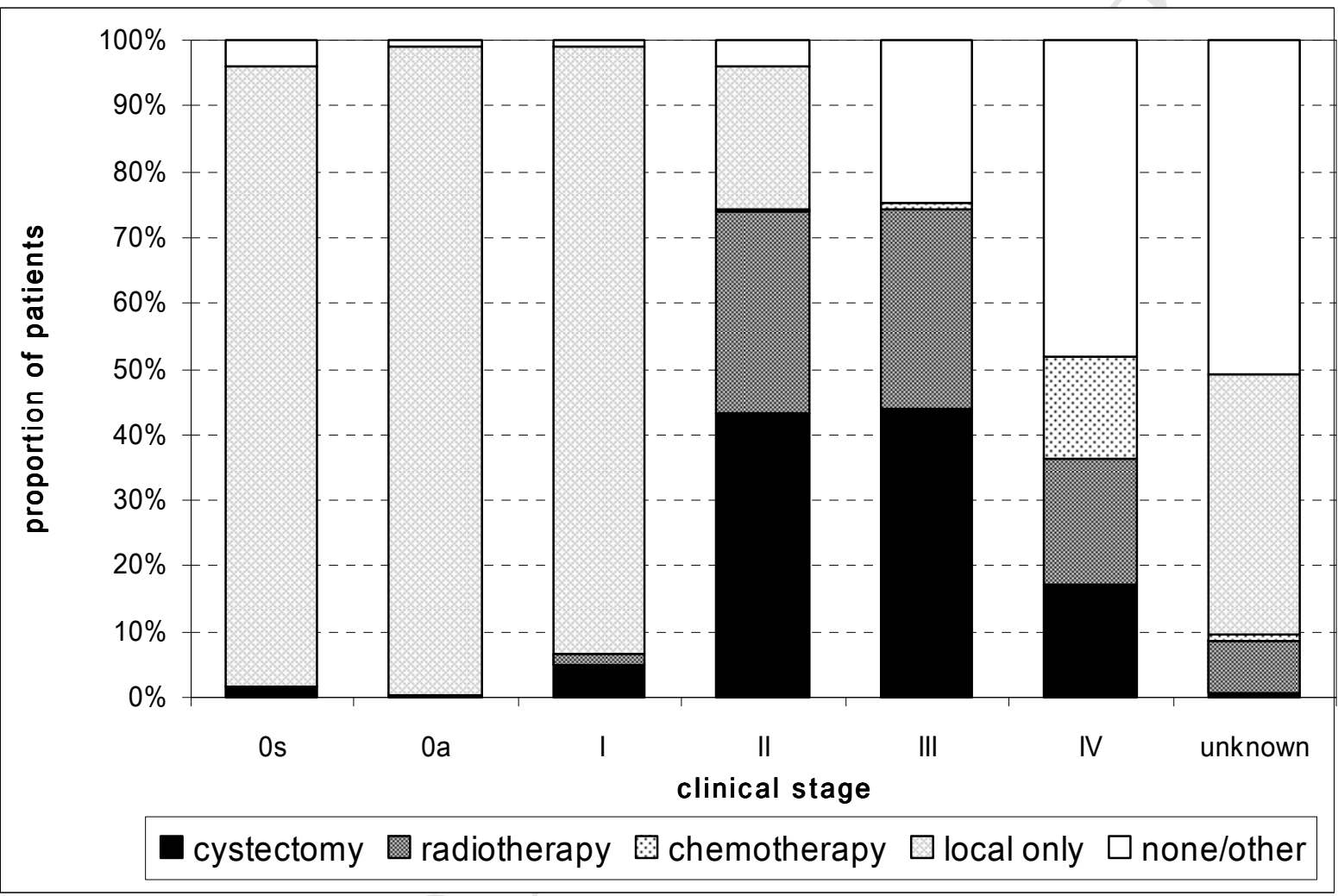


419 Figure 2

420 Proportion of clinical stage II-III bladder cancer patients treated with cystectomy or

421 radiotherapy according to age category, the Netherlands 2001-2006

422

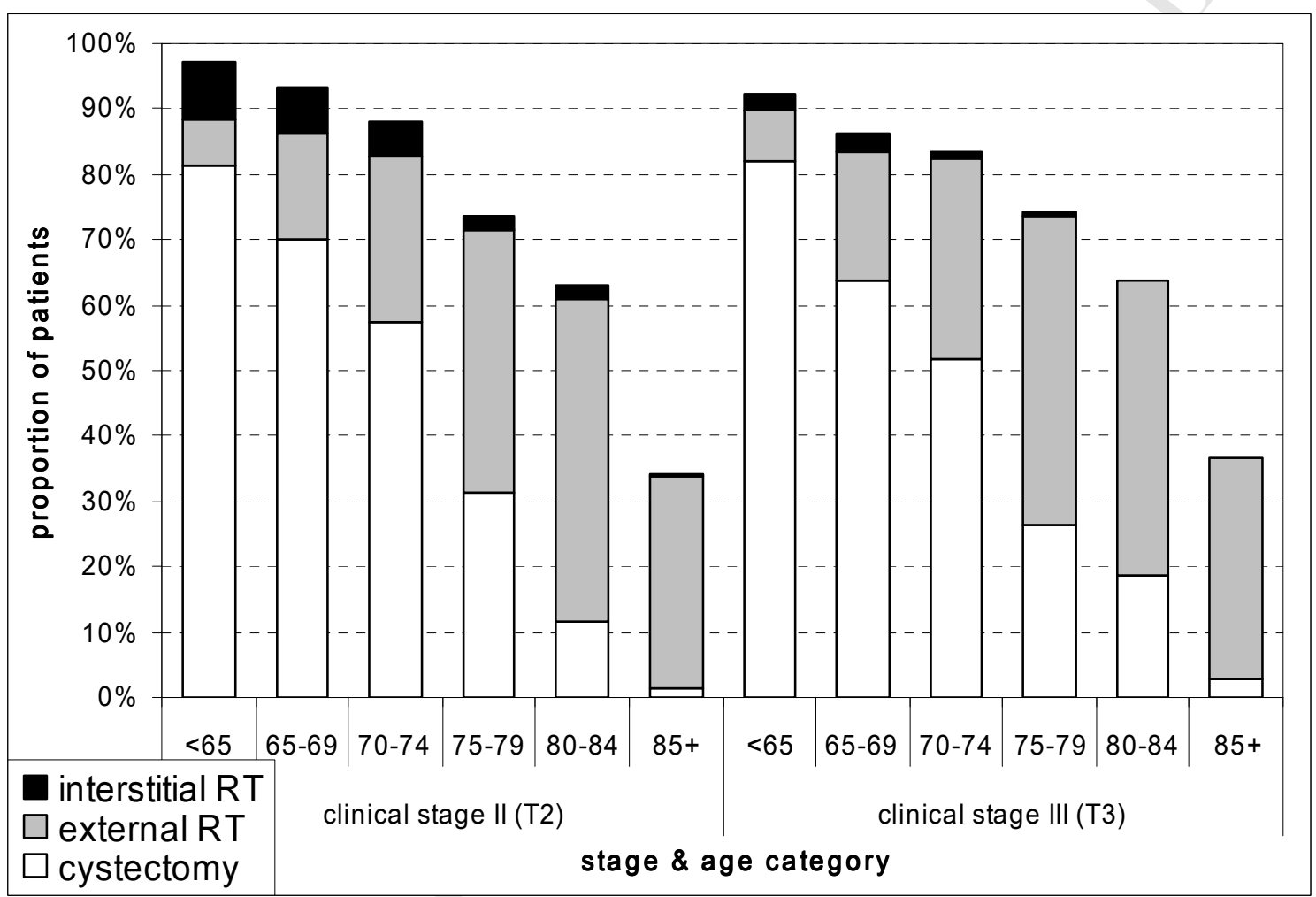

423

424 Interstitial radiotherapy may also be preceded by a short external radiotherapy session. 
425 Figure 3

426 Regional variation in treatment of clinical stage II bladder cancer patients according

427 to age and comprehensive cancer centre region, the Netherlands 2001-2006.



429

430

431

432 
435 Figure 4

436 Number of patients who underwent cystectomy according to average annual number

437 of cystectomies per hospital, the Netherlands 2001-2006.

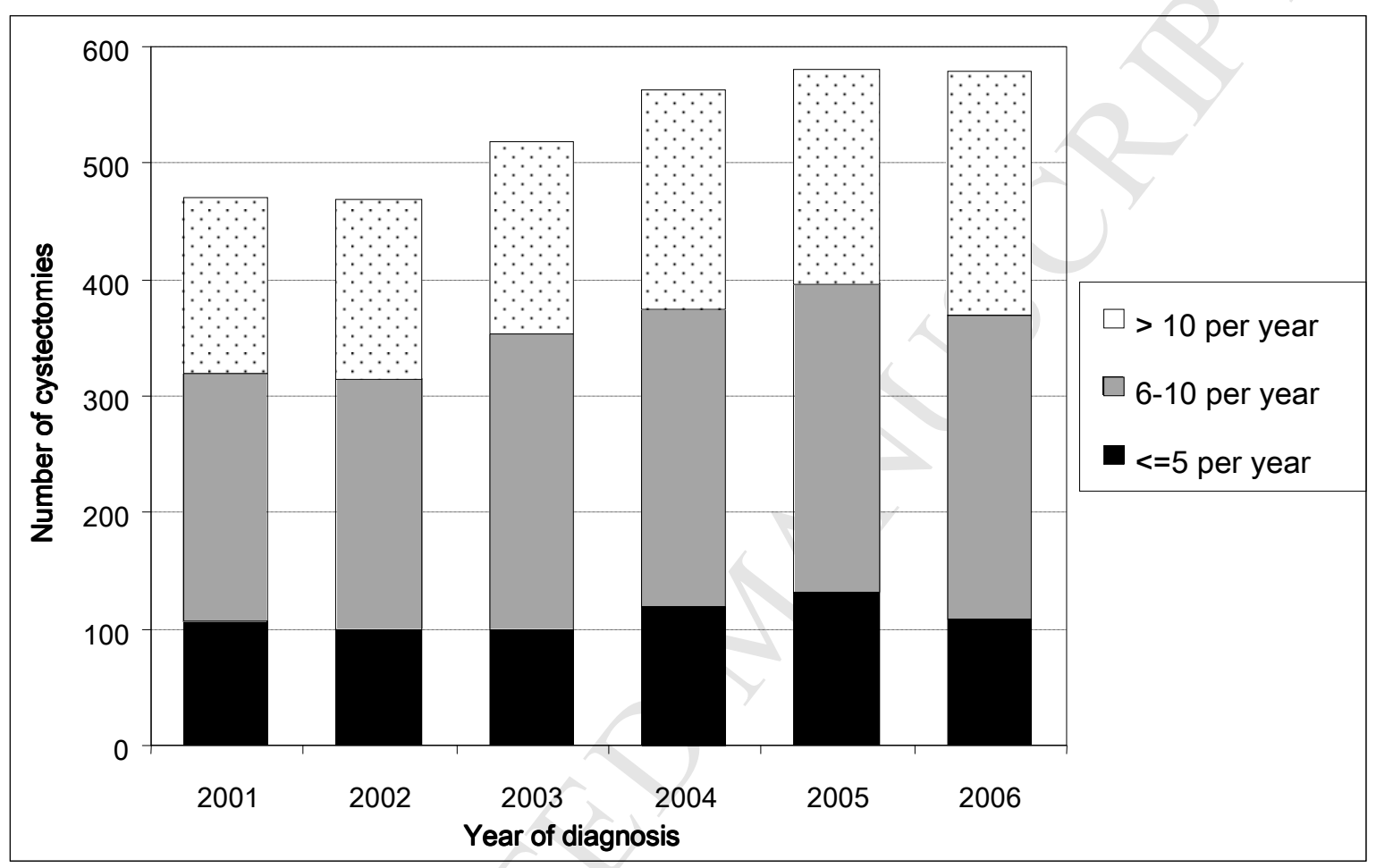

438 